\title{
INFORMACIÓN PARA LAS DECISIONES
}

Dr. PASCUAL CHAVEZ ACKERMANN.(*)

Todos tomamos decisiones. Casi siempre, y a menos que nuestra decisión sea puramente emotiva, usamos información que nos ayuda en nuestra decisión. La información incluye hechos, ideas y conceptos que nos ayudan a comprender el mundo. El uso apropiado de buena información trae consigo mejores decisiones. Al usar la información debemos interpretar y comprender sus limitaciones. La información inadecuada o el mal uso de la información a menudo conducen a decisiones equivocadas.

La contabilidad proporciona información que ayuda a adoptar decisiones en la empresa. Esta información es como un mapa de la organización. La información contable ayuda a quienes adoptan decisiones a saber dónde están, dónde han estado y hacia dónde se dirigen. En lugar de medir la distancia en millas o kilómetros, la contabilidad mide las actividades de la organización con la cantidad de dinero relacionada con dichas actividades. Luego, la principal unidad de medida para la información es el dólar en USA, y la moneda local en otros países. El dólar tiene aceptación casi universal, y por esa razón los datos están consignados en dicha moneda.
Como ejemplo, suponga que decide empezar un negocio como trabajo de verano, vendiendo gafas, trajes de baño y bronceadores en un pequeño stand, llamado apropiadamente "Playa Linda", que alquila del cercano hotel de la playa. Usted tendrá que formular y responder las siguientes preguntas: ¿Es ésta una buena oportunidad para el negocio? ¿Cuánto dinero espera ganar? ¿Está ganando tanto como esperaba? Teniendo en cuenta los principales componentes de su negocio, ¿qué necesitará para empezar? Necesitará mercancías para vender y tendrá que adquirirla de los proveedores. Necesitará un lugar dónde vender y alguien a quien venderle su mercadería. Necesitará dinero para pagar por la mercancía, la renta, sueldos y gastos diversos, como licencia para negocio y publicidad.

Como paso inicial del negocio, usted no puede calcular cuánto espera vender. Discute el proyecto con otros comerciantes y concluye que un pequeño negocio como el suyo, generalmente vende alrededor de US\$ 700 al mes, entre enero y marzo, por ejemplo. Ahora, debe considerar cuánto dinero necesitará para operar su negocio. Suponga que vende mercaderías por US\$ 7000 por las que pagó US\$3500. También

${ }^{*}$ ) Docente Principal de la Facultad de Ciencias Contables de la UNMSM. 
necesitará ayudantes a tiempo parcial para tener el negocio abierto 10 horas diarias, 7 días a la semana. Luego, Ud. determina que necesitará lo siguiente cada mes:

$\begin{array}{lr}\text { Mercaderías US\$ } 3500 \\ \text { Alquiler } & 500 \\ \text { Sueldos } & 1200 \\ \text { Diversos } & 200 \\ \quad \text { Total } & \text { US\$5400 }\end{array}$

También puede calcular cuánto espera ganar en el negocio. Si espera vender por US $\$ 7000$ y sus costos suman US $\$ 5400$ Ud. esperaría ganar US\$1600 al mes o US\$ 4800 (3 x US\$ 1600) durante el verano.
US\$ 5000 en una cuenta de ahorros. Por otro lado, también estaría invirtiendo la mayor parte de su tiempo en el negocio, trabajando 50 horas a la semana. Si no empezara el negocio, podría efectuar alguna otra labor, como trabajar en un restaurante de comida rápida donde pagan US\$ 5 la hora. Trabajando 50 horas a la semana. Ud. ganaría US\$ 3000 (US\$ $5 \times 50$ horas $\times 12$ semanas) del verano. Además, no arriesgaría los US\$ 5000 con los cuales podría ganar intereses en una cuenta de ahorros.

La información del costo y el beneficio no determina su decisión. Usted debe decidir si quiere trabajar en la playa o en el restaurante; si está seguro que ganará en el negocio, y cuál es el riesgo que está dispuesto

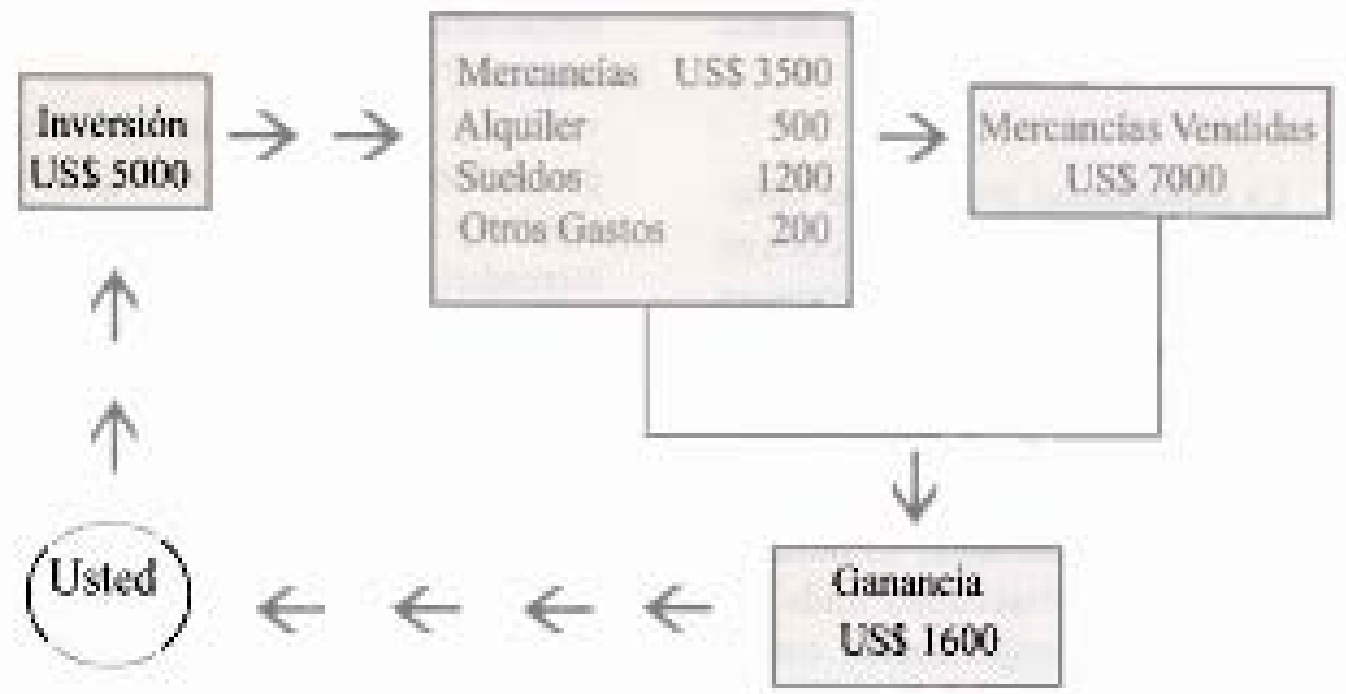

Usted tendrá que decidir si este negocio le conviene. Suponga que debe invertir US\$ $\$ 500$ para adquirir un lote inicial de mercadería y para alquiler, sueldos de la primera semana y gastos diversos. ¿Será buena idea invertir en el negocio? Si gana US $\$ 4800$ por su inversión, obtiene una tasa de interés sobre su inversión (ganancia/ suma invertida) de $96 \%$, US\$ 4800 / US\$ 5000 que invirtió. Luego, al final del verano tendrá US\$9800. Esta utilidad es mucho mayor que lo que recibiría si invirtiera los a afrontar. La inversión en un negocio siempre es riesgosa. El riesgo es la incertidumbre de lo que ocurrirá, o del monto que ganará. Suponga que el verano se torna inesperadamente frío y húmedo. Si vende menos de lo que esperaba, su ganancia será menor. Hasta podría perder dinero. ¿Está dispuesto a correr el riesgo? La contabilidad puede ayudarlo en estas decisiones, con información sobre lo que Ud. espera. Tendrá que evaluar la información y adoptar una decisión. 
La contabilidad es un medio para examinar un negocio. Mide sus actividades a través de sus ingresos y egresos de dinero. Ayuda al empresario a conocer el punto de partida. Por ejemplo, si Ud. invierte US\$ 5000 , le ayuda a saber hasta dónde llegará. Si espera ganar US\$4800 le ayuda a saber si logrará sus expectativas. Suponga que en enero vendió US\$6000 en lugar de los US\$7000 que esperaba. Como en un mapa, la contabilidad le permite saber que no se encuentra donde deseaba y a encontrar el error, $y$ algunas veces, a efectuar modificaciones para volver a la ruta correcta.

La contabilidad facilita un modelo de evaluación del negocio midiendo sus actividades en términos monetarios. Fundamentalmente, este modelo constituye un sistema de información que facilita procedimientos para obtener hechos que se conviertan en información útil. La comprensión del sistema y su procedimiento le ayudarán a entender la información que la contabilidad proporciona.

\section{EL PROCESO CONTABLE}

Objetivo 1.- Determinar el propósito de la contabilidad.

El propósito de la contabilidad es ayudar a la gente en la adopción de decisiones acerca de las actividades económicas. Las actividades económicas implican la distribución de recursos escasos. La gente distribuye recursos escasos cuando intercambia dinero, bienes o servicios. Estas actividades son tan comunes que casi todo adulto en la sociedad actual emplea el proceso contable al adoptar una decisión.

Informe Resumen.- Si Ud. desea saber cuánto gastó en enero y el propósito de los egresos, puede resumir la información pro- veniente de la cuenta conriente, lo que le permitirá comprender tales actividades.

El banco le proporciona un estado que le informa las actividades de su cuenta durante el mes. Dicho estado enumera los depósitos y los cheques emitidos y pagados. El banco le proporciona este informe para que verifique la exactitud de la información de su registro de cheques y la del informe del banco con relación a su cuenta. Ud. verifica dicha exactitud comparando su registro de cheques con el informe del banco.

\section{ETAPAS EN EL PROCESO CONTABLE}

Una cuenta es un registro del aumento o disminución de dinero con relación a una actividad o un recurso específico. Toda la información que Ud. registra en su cuenta corriente constituye una cuenta, la que Ud. tiene en el banco. El registro le permite controlar los ingresos, los egresos y el saldo en su cuenta corriente.

La información de su registro de cheques resume las actividades de su cuenta corriente. Ud. anota en el registro cuando ocurre un aumento o disminución en el dinero de su cuenta. Una transacción es un acto que aumenta o disminuye el saldo de una cuenta. Las transacciones identifican las variaciones en los recursos, y las actividades que los afectan. Por ejemplo, cuando Ud. emite un cheque en pago por mercancías, Ud. cambia dinero de su cuenta corriente por mercancías. Este acto es una transacción que anota en su registro de cheques, indicando el importe del cheque y la reducción de su saldo.

El banco mantiene una cuenta para cada uno de sus clientes. Cada vez que un cliente deposita dinero o emite un cheque, el banco 
registra la transacción en la cuenta del cliente. El saldo es la suma disponible para uso del cliente. El estado mensual bancario resume las transacciones registradas por el banco en la cuenta del cliente. Las actividades relacionadas a una cuenta corriente proporcionan un ejemplo típico de un proceso contable. Este proceso comprende cuatro etapas básicas, que incluyen: dinero. ¿Cuánto gastó en alquileres en el mes pasado? Puede ayudarle a planificar sus gastos futuros. ¿Puede adquirir mercancía adicional? Le da certeza que cuenta con el dinero que supone. La información contable ayuda a adoptar decisiones.

Una organización es un grupo de personas que trabajan en conjunto para el desarrollo, producción y/o distribución

\begin{tabular}{|c|c|c|c|}
\hline Transacción & Registro & Cálculo-Saldo & Informe \\
\hline \multicolumn{2}{|c|}{ Etapas } & \multicolumn{2}{|c|}{ Ejemplo } \\
\hline \multicolumn{2}{|c|}{$\begin{array}{l}\text { 1. La transacción se realiza. } \\
\text { 2. Registro de la transacción en } \\
\text { una cuenta apropiada. } \\
\text { 3. Cálculo del saldo de la cuenta. }\end{array}$} & \multicolumn{2}{|c|}{$\begin{array}{l}\text { 1. Se adquieren mercancías } \\
\text { 2. Registro del pago en la cuenta } \\
\text { de cheques. } \\
\text { 3. Resta del importe del cheque } \\
\text { del saldo. } \\
\text { 4. Preparación del resumen de la } \\
\text { cuenta corriente por las } \\
\text { actividades del mes. }\end{array}$} \\
\hline
\end{tabular}

Objetivo 2.- Demostrar que la contabilidad es un sistema de información.

Un sistema es un grupo de actividades o procesos relacionados que actúan en conjunto para lograr un objetivo. Debido a que comprende el registro, resumen y emisión de la información económica empleada en la adopción de decisiones, la contabilidad constituye un sistema de información.

\section{Uso de la Información Contable}

Las decisiones adoptadas por el usuario de un sistema de información contable la clase de información emitida por el sistema. Un registro de cheques y su estado de cuenta son ejemplos de información contable. Están para ayudar al depositante. La información de su cuenta corriente puede ayudarle a saber cómo ha empleado su de bienes o servicios. Las organizaciones comerciales venden bienes o servicios a los clientes. Algunas organizaciones, como las sociales y las religiosas, proporcionan servicios a sus miembros u otros receptores. La contabilidad proporciona información a los administradores, propietarios, miembros $\mathrm{u}$ otros accionistas, quienes adoptan decisiones acerca de la organización. Los accionistas incluyen a todos aquellos que tienen un interés económico en una organización o son afectados por sus actividades.

Objetivo 3.- Comparar los diferentes tipos de organizaciones.

Existen muchos tipos de organizaciones al servicio de la sociedad. ¿Por qué existen? La mayoría existen porque las personas necesitan trabajar en conjunto para lograr 
sus objetivos, los cuales son demasiado grandes, complejos o costosos de alcanzar sin colaboración. Todas las organizaciones proveen bienes $y / o$ servicios.

Las organizaciones se distinguen por el tipo de bienes o servicios que ofrecen. Las compañías comerciales venden bienes producidos por otras compañías como en las tiendas por departamentos, bodegas, ferreterías, etc. La tienda "Playa Linda" es una compañía comercial porque adquiere mercaderías de los proveedores para luego venderlas a sus clientes. Las compañías manufactureras producen bienes que venden a los consumidores, a las compañías comerciales o a otras compañías manufactureras, como ocurre en las fábricas de automóviles, refinerías de petróleo, fabricantes de muebles, compañías papeleras, de computadoras, etc. Las compañías de servicios ofrecen servicios en lugar de bienes. Estas compañias incluyen a los bancos, compañías de seguros, hospitales, colegios, estudios de abogados y de contabilidad. Algunas compañías combinan varios tipos. Los restaurantes son compañías manufactureras y de servicios. ciones gubernamentales o no comerciales se refieren a las que proporcionan bienes o servicios sin el propósito de obtener ganancias. Estas organizaciones conocidas como organizaciones sin fines de lucro, incluyen a las organizaciones cívicas, sociales y religiosas. Algunos servicios son proporcionados tanto por organizaciones lucrativas como sin fines de lucro, como los servicios de educación y salud. Aunque los servicios sean similares, las entidades se diferencia por el propósito que persiguen. Sea como fuere, la información contable es necesaria en todas las organizaciones para la adopción de decisiones.

\section{Transformación de Recursos}

El propósito de la mayoría de las organizaciones es transformar recursos de una forma en otra de diferente tipo o mayor valor para satisfacer las necesidades de la población. Los recursos comprenden a los recursos naturales, como los minerales, la madera, etc.; los recursos materiales, como edificios y equipo, la experiencia administrativa, laboral y financiera, los derechos

\section{Tipos de Organizaciones}

\begin{tabular}{|l|c|}
\hline Comerciales & No Comerciales \\
\hline Ventas al detalle & Gubernamentales \\
\hline Manufactureras & Otras sin fines de lucro \\
\hline De Servicios & \\
\hline
\end{tabular}

Las organizaciones se clasifican según procuren o no obtener ganancias. Estas ganancias provienen de la venta de bienes o servicios a precios mayores que los que se nagaron por su adquisición o producción. Las organizaciones que venden bienes o servicios para obtener ganancias se conocen como organizaciones comerciales o con fines de lucro. Las organiza- legales como de marca y patentes, los sistemas que proveen información, etc. El proceso de transformación combina estos recursos para producir bienes y servicios. La transformación puede facilitar la obtención más fácil y menos onerosa de bienes, como ocurre en muchas compañías comerciales, o la conversión física de los recursos como en las compañías manufactureras. En 
la tienda "Playa Linda" se transforman recursos adquiriendo mercancías y poniéndolas a disposición de los clientes que las necesitan mientras permanecen en la playa.
CREACIÓN DEL VALOR

Objetivo 5.- Explicar la importancia de los mercados.

\section{Transformación de Recursos}
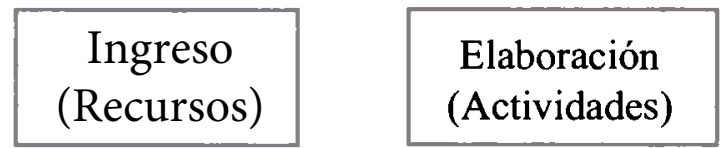

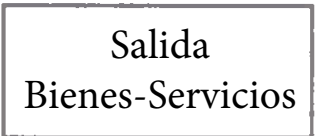

Objetivos 4.- Explicar la contribución de las organizaciones en la sociedad.

Las organizaciones se crean porque muchas realizaciones son costosas y dificiles de lograr individualmente, por lo que es necesario el trabajo colectivo. Combinando conocimientos, trabajo y dinero los individuos crean organizaciones para lograr beneficios que de otro modo no se podrían obtener. Tales beneficios se logran cuando las organizaciones transforman y/o modifican los recursos que se encuentran en estado poco utilizable en otro más accesible y atrayente.

La transformación cuando encuentra una necesidad en la sociedad, crea valor porque la gente se encuentre mejor después de la transformación que antes. Por ejemplo, una empresa que fabrica camisas, crea valor porque las camisas son más útiles para quienes las compran que el algodón o la fibra sintética con que se fabrican. Para mejorar su bienestar, la sociedad debe estimular el aumento del valor creado por las empresas. Debido a la escasez de recursos, la sociedad debe procurar su uso adecuado. El propósito principal de la información contable es ayudar a encontrar la manera de aprovechar mejor el valor de los recursos escasos.
¿Cómo determina la sociedad la manera de usar los recursos? No es fácil determinar el uso adecuado de los recursos escasos. Debido a que la sociedad está conformada por muchos individuos, existen desacuerdos sobre la manera de usar los recursos. En nuestra sociedad y en muchas otras, los mercados son el medio para promover el uso adecuado de los recursos.

El propósito de los mercados es la distribución de los recursos empleados $\mathrm{y} / \mathrm{o}$ producidos por las empresas. Un mercado es cualquier lugar o procedimiento que permite la compra y venta de recursos. La competencia en el mercado determina la cantidad y el valor de los recursos disponibles para el intercambio. A mayor capacidad de un recurso de satisfacer necesidades, mayor será el precio pagado por su compra o el precio cobrado en la venta.

El precio pagado por un recurso es el valor que se le asigna en un mercado competitivo en el momento en que el comprador y el vendedor negocian un intercambio. Por ejemplo, al comprar un automóvil Ud. cambia dinero por el automóvil. La suma de dinero es el valor que Ud. le asigna al automóvil. La contabilidad mide el aumento en el valor creado por la transformación, como la diferencia entre el precio total de los bienes o servicios vendidos y el costo total de los 
recursos empleados en el desarrollo, producción y venta de dichos bienes y servicios.

Nota Instructiva.- Diferencia entre el precio cobrado por un comerciante a sus clientes y el que pagó al obtener los recursos que empleó: el precio cobrado por el comerciante es el precio de venta, mientras que el precio que pagó por los recursos empleados para producir los bienes o servicios es el precio de costo.

¿Qué representa el precio de un automóvil? El precio que Ud. pagó por el automóvil es un índice del valor que Ud. espera recibir al poseerlo. Pero para producirlo y ponerlo a su disposición se emplearon recursos:
Ganancia, es la diferencia entre el precio que el vendedor recibe por la venta de bienes y servicios y el costo total de los recursos empleados en el desarrollo, producción y venta de dichos bienes y servicios en un período determinado. Luego, la ganancia representa el producto neto generado en la venta (recursos obtenidos por la venta menos los recursos empleados en dicha venta).

Nota Instructiva.- El periodo es un concepto importante en contabilidad. Un periodo puede ser cualquier extensión de tiempo usado para medir los efectos de las transacciones. Generalmente, los períodos se refieren a meses, trimestres o años. Un período contable también es conocido como período fiscal porque puede no coincidir con el
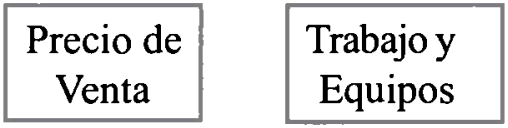

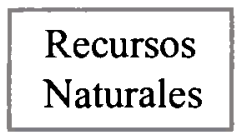

Valor

Agregado
El costo total de los recursos, como metales, plásticos, caucho, tapicería, maquinaria y el trabajo de manufactura empleado en la producción, el costo del dinero para adquirir otros recursos y el transporte hasta el distribuidor, es el costo de los recursos empleados para poner el automóvil a su disposición. El aumento del valor producido por la fabricación del automóvil es la diferencia entre el precio que Ud. pagó y el costo total de los recursos empleados.

Por ejemplo, si Ud. paga US\$ 12000 por un automóvil y el costo total de producirlo y ponerlo a su disposición es US\$ 10000 , el valor agregado por la transformación es de US\$2000. La diferencia entre el precio que Ud. pagó y el costo total para el vendedor es la ganancia del fabricante y del vendedor del automóvil. período calendario. Por ejemplo, el período fiscal de una empresa puede empezar el 01 de julio.

Algunos mercados son importantes en nuestra economía. Existen mercados para los recursos empleados por las empresas que compiten en mercados financieros para conseguir recursos. Los inversionistas eligen dónde colocar su dinero escogiendo entre organizaciones competidoras. Las empresas compiten en los mercados de proveedores por los recursos que necesitan para producir bienes y servicios. La competencia en estos mercados determina el costo de los materiales, del trabajo, equipo y otros recursos. Las organizaciones compiten en mercados de productos (de bienes y servicios). Estos mercados determinan los precios de los bienes y servicios a disposición de los 
consumidores. Desde el punto de vista de las empresas, los mercados financieros y de proveedores son mercados de ingreso, y los mercados de bienes y servicios son mercados de salida. Todos estos mercados distribuyen los recursos escasos.

\section{INVERSIÓN DEL PROPIETARIO}

Objetivo 6.- Explicar por qué los propietarios invierten en negocios.

Los negocios obtienen ganancias (ingresos netos) al proveer bienes y servicios que la sociedad necesita. Los propietarios invierten en negocios para obtener una ganancia por su inversión proveniente de las utilidades generadas por el negocio. Al invertir, los propietarios anteponen la inversión a cualquier otro uso que podrían darle a su dinero. A cambio, esperan participar de las utilidades obtenidas por el negocio. La ganancia de la inversión es la suma de las utilidades obtenidas por un negocio paras ser distribuidas entre los propietarios. La ganancia de un negocio siempre se expresa como un porcentaje: Ganancia/suma invertida.

Las ganancias representan las utilidades netas percibidas como resultado de las ventas. El negocio está en condiciones de distribuir utilidades entre sus propietarios. Asimismo, los dueños (o los administradores que actúan en su representación) pueden optar por reinvertir las utilidades en otros negocios para obtener utilidades adicionales.

\section{MERCADO DE INVERSIONISTAS}

Objetivo 7.- Explicar por qué la información contable es útil a los inversionistas.

El sistema de información contable es la principal fuente de información que los inversionistas emplean para decidir acerca de sus inversiones. La información contable ayuda a los inversionistas a evaluar la eficacia y eficiencia de las empresas. Les ayuda a estimar las ganancias que podrían esperar y el riesgo ligado a una inversión. Los mercados financieros, de proveedores y de productos, crean incentivos para que las empresas provean los productos que la sociedad requiere. Las obliga a asegurar el empleo de los recursos escasos para mejorar el bienestar de la sociedad. Los mercados ayudan a colocar los recursos en las organizaciones que pueden transformarlos mejor para crear valor.

\section{DECISIONES EN LA ORGANIZACIÓN}

En las organizaciones se adoptan muchos tipos de decisiones. La contabilidad proporciona información importante para tales decisiones. Esta sección estudia tres actividades empresariales en las que se emplea la información contable en la adopción de decisiones sobre actividades operativas, financieras y de inversión.

\section{ACTIVIDADES FINANCIERAS}

Objetivo 8.- Identificación de las actividades financieras y el tipo de decisiones que requieren.

Las organizaciones necesitan recursos para conseguir medios para producir bienes y servicios. Compiten por tales recursos en los mercados financieros. Las actividades financieras son métodos que la empresa emplea para conseguir recursos en los mercados financieros y para administrar dichos recursos. Las principales fuentes de financiamiento en muchos negocios con los propietarios y los acreedores. 
Objetivo 9.- Comparar las diferentes clases de propiedad empresarial.

Propiedad Empresarial.- Las empresas se clasifican en dos categorías: Las que constituyen una entidad legal distinta a la de sus propietarios y las que constituyen una sola entidad legal con los propietarios. Una corporación es una entidad legal que tiene capacidad para celebrar contratos, poseer, comprar y vender bienes y productos de la empresa y emitir acciones. Los recursos son de propiedad de la corporación y no de sus integrantes individuales.

Las corporaciones pueden ser muy grandes o relativamente pequeñas. Las empresas pequeñas son administradas por sus dueños. Los dueños de las corporaciones no las administran directamente. Para ello, contratan administradores profesionales. Los dueños de estas empresas tienen derecho de voto en las decisiones importantes, pero no controlan directamente las operaciones diarias. La razón por la que la mayoría de las empresas grandes se organizan como corporaciones es porque de esa manera tienen mayor acceso a los mercados financieros, en comparación otros tipos de organizaciones.

\section{ACTIVIDADES DE INVERSIÓN}

Objetivo 10.- Identificar las actividades de inversión y el tipo de decisiones que requieren.

Los administradores emplean el capital proveniente de las actividades financieras para adquirir otros recursos y emplearlos en el proceso de transformación. Lograr la combinación correcta de recursos es crucial para una operación eficaz y eficiente. La disposición errónea de recursos o su obtención en momento o lugar inadecuados puede ocasionar resultados desastrosos.
La actividades de inversión comprenden la selección y administración de recursos empleados en el desarrollo, producción y venta de bienes y servicios. Los recursos incluyen suministros, seguros, terrenos, recursos materiales, edificios, equipos, sistemas de información, personal, derechos legales como patentes y marcas, y otros recursos necesarios en la empresa para producir bienes y servicios. Las organizaciones compiten para obtener dichos recursos en los mercados de proveedores.

Decisiones de inversión.- Los administradores deciden cuánto invertir en recursos y qué tipo de recursos adquirir. Casi siempre estas decisiones implican grandes sumas de dinero y tienen gran efecto en el futuro de una organización. Afectan el futuro de la rentabilidad, del abastecimiento de bienes y servicios y del pago a los dueños y acreedores.

Para adoptar decisiones de inversión, los administradores necesitan información para predecir la futura demanda de bienes y servicios. Necesitan saber qué productos tendrán demanda, cuánto y en qué cantidad, y el precio que los consumidores estarán dispuestos a pagar. Esta información es necesaria para saber qué tipo de recursos se requieren para producir los bienes y servicios que los clientes necesitan. Además, los administradores necesitan información de la actual disponibilidad de recursos y cómo serán empleados. Necesitan saber qué, cuándo y cuánto se podrá producir, y cuánto costará producirlo. Evalúan las alternativas de adquisición đde recursos, por ejemplo, podrian ser adquiridos, arrendados o alquilados. 
Objetivo 11.- Identificar las actividades operativas y el tipo de decisiones que requieren.

Las actividades operativas comprenden el empleo de recursos para diseñar, producir y distribuir y vender bienes y servicios. Estas actividades incluyen la investigación y desarrollo, diseño, ingeniería, adquisiciones, recursos humanos, producción, distribución, mercadeo, venta y servicio. Las organizaciones compiten en los mercados laborales y de proveedores en procura de recursos empleados en estas actividades.

Los componentes de las actividades operativas de una compañía:

- Investigación y Desarrollo.- Las actividades de investigación y desarrollo crean nuevos productos y actualizan los productos y procesos productivos obsoletos. Muchas compañías operan en un entorno altamente competitivo y deben mantenerse informadas de los rápidos cambios en la tecnología y preferencia de los consumidores, como acontece en la manufactura de computadoras y de productos farmacéuticos. Este entorno obliga a las empresas a mejorar constantemente sus productos, a encontrar otros nuevos que satisfagan las necesidades del consumidor y la manera de reducir el costo de producirlos. Las compañías de servicios se ocupan de la investigación y desarrollo, cuando identifican nuevos servicios.

- Diseño e Ingeniería.- Estas actividades determinan el diseño de los productos, el proceso de producción, las facilidades y el sistema de distribución. Los requerimientos de equipo y labor del proceso de manufactura, ensamblaje y similares, de la manera cómo los productos son elaborados y distribuidos, tienen el mayor efecto en el costo y probalidades de venta del producto.

- Adquisiciones.- Estas actividades incluyen la compra y administración de materiales y suministros necesarios para la producción y venta. Los materiales empleados en la manufactura deben ser adquiridos en cantidades apropiadas y en el momento oportuno para asegurar su disponibilidad. Los materiales son de adquisición y almacenamiento costoso, pero la producción no se efectúa a menos que se cuente con el material necesario y en cantidad adecuada. Las decisiones de adquisición incluyen la elección del tipo apropiado, la calidad y cantidad de materiales para minimizar los costos de adquisición, almacenamiento y producción. Esta función es también importante en las compañías mercantiles donde las actividades de adquisición controlan la selección y compra de bienes disponibles para la reventa y también son importantes en las organizaciones de servicios, como los hospitales.

- Recursos Humanos.- Además de los materiales, el trabajo es un factor principal en la producción y venta de bienes y servicios. La actividad de recursos humanos comprende la obtención de la cantidad necesaria de personal con capacitación adecuada. Las funciones principales incluyen la contratación, despido y capacitación de trabajadores y la coordinación de planillas de salarios y beneficios, comojubilación y cuidado de la salud. La negociación de los salarios y la atención del bienestar de los trabajadores también pueden ser responsabilidades importantes en la función de personal.

- Producción.- Las actividades de producción comprenden la manufactura y ensamblaje de bienes para su venta. Se deben adoptar disposiciones para programar el proceso de producción, para tener a disposición el personal, los materiales y equipo necesarios. La combinación adecuada de 
estos factores es necesaria para asegurar la calidad y cantidad de bienes a producir. Las decisiones de producción afectan el costo y la calidad de los productos. La mayoría de las empresas controlan cuidadosamente el proceso de producción para mejorar los costos y la calidad.

- Distribución.-La distribución constituye la actividad primordial en muchas compañías, cuya principal labor de transformación consiste en situar los bienes en el lugar apropiado para comodidad de los clientes. También es importante en muchas compañías manufactureras y de servicios. Las actividades de distribución incluyen la obtención de bienes apropiados en el lugar y momento adecuados. Debido a que el transporte es costoso se debe decidir cómo y dónde embarcar los bienes y en qué cantidades. Las actividades de distribución son especialmente importantes en las compañías que operan en mercados globales, donde las mercancías deben ser embarcadas desde el país donde son producidas hacia aquel en que son consumidas.

- Ventas y Mercadeo.- Las actividades de venta y mercadeo incluyen la difusión de los productos entre los compradores potenciales y su venta a los consumidores. El suministro de información a los compradores potenciales por medio de avisos, publicidad y contactos personales es esencial en la mayoría de las empresas. Los administradores deciden cómo llegar efectivamente a los compradores y la manera de presentar los productos para generar su venta. Las decisiones incluyen la intensidad y el tipo de publicidad, el personal necesario, la clase y cuantía de los descuentos y créditos a los diferentes compradores y el conocimiento de las necesidades y deseos de los consumidores. Por consiguiente, la venta va más allá de la venta actual, implica la observación cuidadosa de las necesidades y gustos del consumidor. A su vez, esta información es im- portante para guiar las iniciativas de investigación y producción en la compañía para producir la cantidad y tipo de bienes y servicios que demandan los clientes.

- Servicio.- La venta de bienes y servicios no es la etapa final del proceso de transformación en muchas organizaciones. El servicio a los productos continúa después de la venta. Las actividades de servicio incluyen la asistencia a los clientes después de la venta de bienes. Las compañías otorgan garantía a muchos productos que requieren reparación o cambio de mercancías defectuosas. Además, los fabricantes o vendedores siempre ofrecen servicio después del período de garantía. Algunas organizaciones ofrecen instalación y mantenimiento por los productos que venden. Por ejemplo, las compañías de computadoras generalmente acuerdan la instalación de sistemas de cómputo y el entrenamiento de empleados para usarlas. Las computadoras, los automóviles y otros productos de alta tecnología necesitan mantenimiento periódico después de su venta.

- Generación de Rentabilidad.- En resumen, esta sección ha descrito las actividades operativas observadas en la mayoría de las organizaciones, aunque no todas existen o existirán en cada una de ellas. La rentabilidad de una compañía depende del éxito de sus ventas y del control de sus costos. La rentabilidad mide la eficiencia en la administración del capital y los recursos. El modo de funcionamiento de la empresa depende de las estrategias particulares elegidas por la administración. Dichas estrategias pueden incluir la provisión de bienes y servicios a menor costo que la competencia, o de bienes y servicios diferentes. Las diferencias pueden apreciarse en el rendimiento, calidad y características del producto. 
Mediante las decisiones operativas, se puede responder las siguientes preguntas:

Investigación y Desarrollo.- ¿Cómo se puede producir nuevos productos o mejorar los existentes?

Ingeniería.- ¿Cómo se puede diseñary producir los productos?

Adquisiciones.- ¿Qué cantidad y clase de recursos se debería adquirir para emplearlos en la producción de bienes y servicios?

Personal.- ¿Qué cantidad y clase de trabajadores se requiere?

Producción.- ¿Cómo planificar las actividades de producción? ¿Se debería producir en el país o en el extranjero?

Distribución.- ¿Cómo almacenar y embarcar los bienes para que los clientes dispongan de ellos cuando los necesiten?

Ventas y Mercadeo.- ¿Qué actividades son necesarias para promover la venta y servicio de bienes?

Servicio.- ¿Qué tipo de servicios de instalación y reparación debe darse a los clientes por los bienes adquiridos?

\section{RESUMEN DEL PROCESO DE TRANSFORMACIÓN}

Objetivo 12.- Enumerar las etapas del proceso de transformación en una organización.

La información es necesaria para la adopción de decisiones en las actividades de financiamiento, investigación y operación. El sistema de información contable está diseñado para satisfacer estas necesidades de información, en particular, en lo que concierne a los efectos financieros del proceso de transformación. El proceso de transformación es un ciclo que comienza con la adquisición de capital proveniente de los dueños y los acreedores. Este capital es invertido en facilidades, equipo, personal y otros recursos necesarios pra bienes y servicios. Las organizaciones emplean estos recursos para el desarrollo, producción, distribución y venta de bienes y servicios. La venta de bienes y servicios origina el ingreso de recursos financieros adicionales para que el ciclo pueda continuar.

Mientras que el flujo de recursos comienza en las decisiones de financiación y se dirige hacia las de investigación y operación, la información casi siempre sigue el camino inverso. Por ejemplo, las decisiones acerca de la cantidad y tipo de productos que los clientes requieren son necesarios antes de que los productos puedan ser diseñados. Estas decisiones son necesarias para planificar las actividades de producción y distribución. La cantidad de unidades producidas afecta las necesidades de materiales, trabajo y equipo empleado en el proceso de producción. Esto determina la necesidad de financiamiento para proveer dinero para dichos recursos. Luego, la planificación siempre comienza con las expectativas de venta de bienes y servicios y actúa retrospectivamente para determinar los recursos y actividades necesarios para producir los bienes y servicios. Asegúrese de comprender cómo las organizaciones transforman los recursos en bienes y servicios.

La información contable proporciona un resumen del proceso de transformación, del mismo modo que un mapa facilita el resumen de una posición geográfica. 


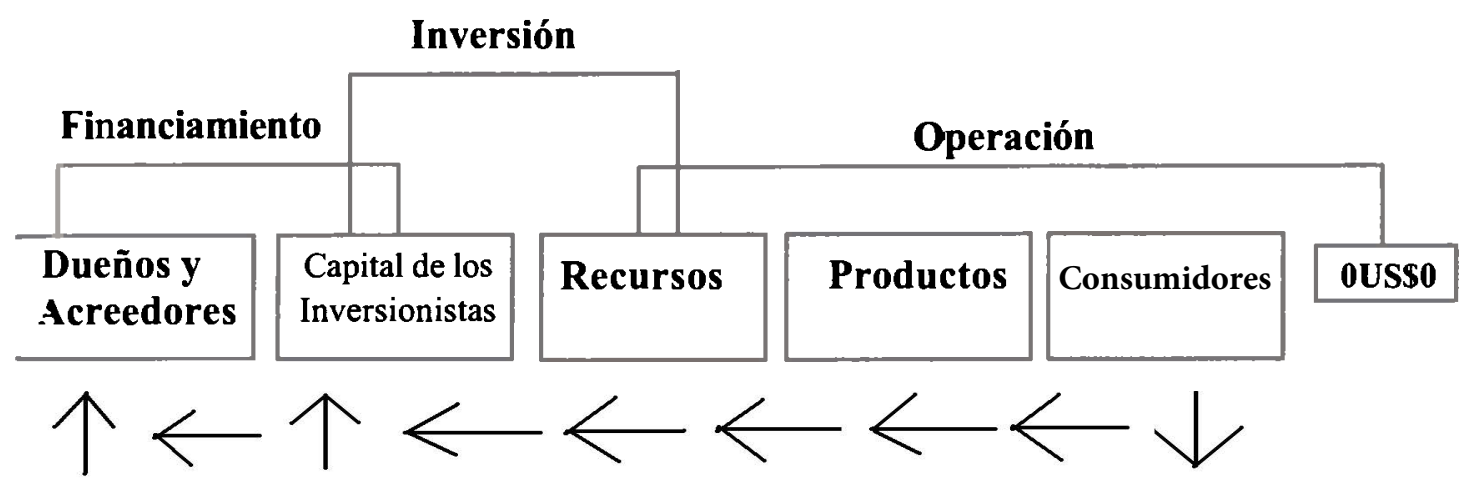

Utilidades Reinversión
CONCEPTOS IMPORTANTES:

\section{1.- El Proceso Contable:}

a.- La contabilidad es un sistema de información para el registro, resumen e informe de los efectos financieros de eventos económicos que ayuda a adoptar decisiones.

b.- La cuenta es la unidad básica de información contable. El efecto de las transacciones se registra en cuentas.

c.- El proceso contable típico incluye: 1) La ocurrencia de un evento a ser contabilizado; 2) El registro de los efectos de los eventos en las cuentas; 3) Cálculo del saldo de las cuentas; y 4) Resumen de los eventos registrados en un periodo y el informe de dicho resumen.

\section{2.- Las organizaciones:}

a.- Existen para servir a la sociedad, transformando recursos de una forma en otra más valiosa para satisfacer las necesidades de la gente. configuran a las empresas e influyen en las necesidades de información de quienes adoptan decisiones. 
b.- Debido a su escasez, la sociedad trata de emplear sus recursos para obtener el mayor beneficio para sus miembros.

c.- Los mercados permiten expresar su concepto del valor de los bienes y servicios a través de los productos que adquieren y los precios que pagan. El aumento del valor creado por el proceso de transformación se puede medir por el precio total de los bienes y servicios vendidos, menos el costo total de los recursos empleados para producirlos.

d.- Los dueños invierten en un negocio para obtener ganancias por su inversión provenientes de las utilidades. Las empresas que operan con eficacia y eficiencia normalmente generan mayores utilidades.

e.- Los negocios que no son rentables dificilmente atraen a los inversionistas y deberán cambiar su modo de operar o retirarse. Por lo tanto, los mercados ponen los recursos financieros y de otra índole a disposición de las organizaciones que los emplean mejor, transformándolos para servir a la sociedad.

\section{3.- Decisiones de Organización:}

a.- Los administradores, propietarios y acreedores necesitan información para apreciar la eficacia y eficiencia de una organización, para proteger sus intereses y evaluar el riesgo y las utilidades de una inversión.

b.- El proceso de transformación comprende la conversión de recursos en bienes y servicios. Este proceso se puede dividir en: actividades financieras, de inversión y actividades operativas.

c.- Las decisiones financieras se adoptan en una organización para obtener recursos financieros. Las empresas obtienen capital de los dueños (propietarios, socios, accionistas), y de los acreedores.

d.- Las decisiones de inversión comprenden las opciones de los acreedores acerca de los recursos empleados para producir bienes y servicios.

e.- Las decisiones operativas incluyen la elección de la manera de transformar los recursos en bienes y servicios. Se decide sobre el diseño y desarrollo de productos, adquisición de materiales, selección y capacitación del personal, del proceso de producción y del mercadeo, distribución y servicio a los productos. 